\title{
Molecular, biological characterization and drug sensitivity of chidamide-resistant non-small cell lung cancer cells
}

\author{
SONG'E LUO ${ }^{1}$, KAI MA ${ }^{2}$, HONGXIA ZHU ${ }^{2}$, SHUREN WANG ${ }^{2}$, MEI LIU $^{2}$, \\ WEINA ZHANG ${ }^{2}$, SHUFANG LIANG ${ }^{1}$ and NINGZHI XU ${ }^{1,2}$
}

\author{
${ }^{1}$ State Key Laboratory of Biotherapy and Cancer Center, West China Hospital, Sichuan University, and \\ Collaborative Innovation Center for Biotherapy, Chengdu, Sichuan 610041; ${ }^{2}$ Laboratory of Cell and Molecular \\ Biology \& State Key Laboratory of Molecular Oncology, Cancer Institute \& Cancer Hospital, Chinese \\ Academy of Medical Sciences and Peking Union Medical College, Beijing 100021, P.R. China
}

Received February 25, 2016; Accepted January 19, 2017

DOI: $10.3892 / 01.2017 .7060$

\begin{abstract}
Chidamide, a histone deacetylase (HDAC) inhibitor, has been applied in clinical trials for various types of hematological and solid tumors. Although acquired resistance is common in chemotherapy, the mechanism of resistance to chidamide is poorly characterized. The goal of the present study was to explore, in detail, the mechanism for the induced resistance to chidamide, and investigate a potential cross-resistance to other chemotherapeutic drugs. A549 cells were exposed to gradually increasing chidamide concentrations to establish a chidamide-resistant non-small cell lung cancer cell line (A549-CHI-R). The $\mathrm{IC}_{50}$ for chidamide, the proliferation inhibition rate, the total HDAC activity and the HDAC protein level were determined by an MTT assay, colony formation, a fluorometric HDAC activity assay and western blotting, respectively. Overexpression of the HDAC1 gene and HDAC1 gene-knockdown were achieved via plasmid transfection. A549-CHI-R cells demonstrated increased resistance to chidamide (8.6-fold). HDAC1 protein degradation was inhibited and HDAC activity was significantly higher in the A549-CHI-R cells relative to the parental A549 cells. A549-CHI-R cells demonstrated cross-resistance to paclitaxel,
\end{abstract}

Correspondence to: Professor Hongxia Zhu or Professor Ningzhi $\mathrm{Xu}$, Laboratory of Cell and Molecular Biology \& State Key Laboratory of Molecular Oncology, Cancer Institute \& Cancer Hospital, Chinese Academy of Medical Sciences and Peking Union Medical College, 17 Panjiayuan Nanli, Chaoyang, Beijing 100021, P.R. China

E-mail: drhxzhu@cicams.ac.cn

E-mail: xuningzhi@cicams.ac.cn

Abbreviations: HDAC, histone deacetylase; A549-CHI-R, chidamide-resistant A549 cells; CDDP, cisplatin; GEM, gemcitabine; 5-FU, 5-fluorouracil; TAX, paclitaxel; VNR, vinorelbine; NSCLC, non-small cell lung cancer

Key words: chidamide, acquired resistance, histone deacetylase 1 degradation, cross-resistant, G2 cell cycle arrest vinorelbine and gemcitabine, but not to cisplatin (CDDP) or 5-fluorouracil (5-FU). These results indicated that HDAC1 may be associated with resistance to chidamide, and HDAC1 may therefore be a predictive marker for chidamide sensitivity in cancer. In addition, A549-CHI-R cells remained sensitive to 5-FU and CDDP, indicating a potential strategy for cancer therapy.

\section{Introduction}

Histone deacetylases (HDACs) are enzymes that remove acetyl groups from histones and a number of non-histone proteins, leading to chromatin condensation and transcription repression (1). To date, 18 HDAC enzymes have been identified in humans, which have been categorized into four classes (2). Class I HDACs including HDAC1, 2, 3 and 8 have been reported to be overexpressed in several cancers, including gastric (3), esophageal (4), colorectal (5), prostate (6) and lung (7) cancer. Aberrant HDAC activity has been detected in a number of types of human cancer, thereby contributing to tumor initiation and progression $(2,8)$. Targeting HDACs is a novel strategy in the development of anticancer drugs (2).

Small molecular HDAC inhibitors (HDACis) are a promising new class of anticancer drugs (9). The USA Food and Drug Administration (FDA) has approved three HDACis: Vorinostat and romidepsin, for the treatment of cutaneous $\mathrm{T}$ cell lymphoma, and belinostat, for the treatment of relapsed or refractory peripheral $\mathrm{T}$ cell lymphoma (10-12). Over 20 chemically distinct HDACis are currently in clinical trials for the treatment of various types of hematological malignancy and solid tumor (13).

Chidamide, a new HDACi, was approved for the treatment of recurrent or refractory peripheral $\mathrm{T}$ cell lymphoma in December 2014 by the Chinese FDA (14). Chidamide selectively inhibits HDAC1, 2, 3 and 10, the HDAC isotypes documented to be associated with malignant phenotypes (15). Chidamide has been applied in clinical trials for various types of hematological malignancy and solid tumor $(14,16)$. Several in vitro studies reported that chidamide alone induced apoptosis, and a combination of chidamide with other chemotherapeutic drugs 
enhanced cell apoptosis in cancer cells $(17,18)$. In addition, chidamide was demonstrated to induce cell apoptosis, cell cycle arrest and cell growth inhibition (17-19).

Acquired resistance to anticancer agents is common in cancer therapy. Previous studies have revealed that the acquired resistance to the HDACi vorinostat is associated with a lack of G2 checkpoint activation and a lack of HDAC6 expression, with an increased level of HDAC1, 2 and 4 expression $(20,21)$. Another HDACi, romidepsin, may cause the reversible induction of multidrug resistance protein expression in tumor cells, leading to transient resistance $(22,23)$. Resistance following chronic treatment with the HDACi valproic acid is associated with elevated Akt activation in renal cell carcinoma in vivo (24).

In the present study, an acquired chidamide-resistant A549-CHI-R cell line was established, with the aim of characterizing in detail the mechanism of chidamide resistance. In addition, the possible cross-resistance to other chemotherapeutic drugs was investigated.

\section{Materials and methods}

Chemicals and reagents. Chidamide was supplied by Shenzhen ChipScreen Biosciences, Ltd., (Shenzhen, China), and was dissolved in dimethyl sulfoxide (DMSO). Cisplatin (CDDP) was obtained from Qilu Pharmaceutical Co. Ltd., (Jinan, China). Vinorelbine (VNR) and gemcitabine (GEM) were purchased from Jiangsu Hansoh Pharmaceutical Co. Ltd., (Jiangsu, China). Paclitaxel (TAX) was obtained from Bristol-Myers Squibb (New York, NY, USA). 5-fluorouracil (5-FU) was obtained from Tianjin Jinyao Amino Acid Co. Ltd., (Tianjin, China). Cycloheximide (CHX) was obtained from Beyotime Institute of Biotechnology (Jiangsu, China). MTT was purchased from Sigma-Aldrich; Merck KGaA (Darmstadt, Germany). RPMI-1640 medium was purchased from Beijing Xigong Biotechnology Co. Ltd., (Being, China). Fetal bovine serum was obtained from Shanghai Ex Cell Biology Inc., (Shanghai, China).

Cell culture and establishment of chidamide-resistant cell lines. The human non-small cell lung cancer (NSCLC) A549 cell line was purchased from the Cell Bank of the Cancer Institute, Chinese Academy of Medical Science (Beijing, China). Cells were cultured in RPMI-1640 medium containing $10 \%(\mathrm{v} / \mathrm{v})$ fetal bovine serum at $37^{\circ} \mathrm{C}$ in a humidified atmosphere with $5 \%(\mathrm{v} / \mathrm{v}) \mathrm{CO}_{2}$. A549 cells were exposed to gradually increasing chidamide concentrations of $4,8,16$, 32 and $64 \mu \mathrm{M}$ for $\sim 6$ months, and a chidamide-resistant lung cancer cell line was established, designated A549-CHI-R.

Growth inhibition. Cell viability was evaluated using an MTT assay. Growing cells $\left(5 \times 10^{3}\right.$ cells/well) were seeded on 96 -well plates with $100 \mu \mathrm{l}$ medium. To assess cell viability, $100 \mu \mathrm{l}$ medium containing serial dilutions (Table I) of chidamide, 5-FU, cisplatin, GEM, VNR or TAX was added, and the cultures were incubated at $37^{\circ} \mathrm{C}$. At $72 \mathrm{~h}$, the medium was discarded, $20 \mu \mathrm{l}$ saline containing $100 \mu \mathrm{g}$ MTT was added to each well and the cells were incubated at $37^{\circ} \mathrm{C}$ for $4 \mathrm{~h}$. The supernatant was removed and $150 \mu \mathrm{l}$ DMSO was added to each well. The absorbance was measured at $570 \mathrm{~nm}$ using a plate reader.
The surviving cell fraction was calculated using the following formula: [(Mean absorbance of test cells-mean absorbance of background)/(mean absorbance of control cells-mean absorbance of background)] x $100 \%$. The $\mathrm{IC}_{50}$ was determined by plotting the logarithm of the drug concentration vs. the percentage of surviving cells. Each assay was performed in quadruplicate at least three times, and the mean and standard deviation were calculated. Percentage inhibition values of compounds were calculated by comparison with DMSO-treated control wells.

Clone formation assay. A total of 800 cells were plated on 6 -well plates. At $24 \mathrm{~h}, 5 \mu \mathrm{M}$ chidamide was added, and the cells were allowed to proliferate. The cell culture medium was replaced when necessary. At $\sim 10$ days, when the differences in the growth of colonies had appeared, the cells were washed with saline, fixed with $100 \%$ methanol at room temperature for approximately $5 \mathrm{~min}$ and dyed with $0.005 \%$ crystal violet (Sigma-Aldrich; Merck KGaA), a chromatin-binding stain, at room temperature for approximately $20 \mathrm{~min}$. The colony formation rates were calculated using the following formula: Number of clones formed/number of seeding cells x $100 \%$.

HDACl gene transfection and knockout. Prior to transfection, $2 \times 10^{6}$ cells were seeded into 6 -well plates. When cells reached $\sim 70 \%$ confluence, they were transiently transfected with a $2 \mu \mathrm{g}$ human HDAC1 plasmid (Invitrogen; Thermo Fisher Scientific Inc., Waltham, MA, USA) or crisper/cas9 HDAC1-knockout plasmid (Viewsolid Biotech Co. Ltd, Beijing, China). Lipofectamine ${ }^{\circledR} 3000$ transfection reagent (Thermo Fisher Scientific Inc.) was used for cell transfection, according to the manufacturer's protocol. At $48 \mathrm{~h}$ post-transfection, total protein or nuclear protein was extracted as described in the subsequent sections, or the cells were seeded at 5,000 per well in 96-well tissue culture plates, and several concentrations ( 0 and $5 \mu \mathrm{M}$ for $\mathrm{A} 549$ or 0 and $50 \mu \mathrm{M}$ for A549-CHI-R) of chidamide were added to assess cell viability.

Western blot analysis. The cells were plated on 6-well plates, allowed to attach for $24 \mathrm{~h}$ and then treated with $5 \mu \mathrm{M}$ chidamide for $72 \mathrm{~h}$, or $10 \mu \mathrm{g} / \mathrm{ml} \mathrm{CHX}$ for $0,4,8,12$ or $24 \mathrm{~h}$. The cells were washed with saline and lysed with radioimmunoprecipitation assay lysis buffer $(20 \mathrm{mM}$ Tris- $\mathrm{HCl}$, $150 \mathrm{mM} \mathrm{NaCl}, 1 \mathrm{mM} \mathrm{Na}{ }_{2}$ EDTA, $1 \mathrm{mM}$ EGTA, 1\% NP-40, $1 \%$ sodium deoxycholate, $2.5 \mathrm{mM}$ sodium pyrophosphate, $1 \mathrm{mM} \beta$-glycerophosphate, $1 \mathrm{mM} \mathrm{Na} \mathrm{VO}_{4}, 1 \mu \mathrm{g} / \mathrm{ml}$ leupeptin and $1 \mathrm{X}$ protease inhibitor cocktail). A total of $50 \mu \mathrm{g}$ protein samples (the protein was quantified using the BSA method) were separated on $10 \%$ SDS-PAGE, and were transferred electrophoretically to a nitrocellulose membrane (GE Healthcare, Chicago, IL, USA). Blocking was performed using skimmed milk at room temperature for $2 \mathrm{~h}$. Membranes were then incubated with the following primary antibodies: $\beta$-actin (cat. no. A5441; Sigma-Aldrich; Merck KGaA; 1:5,000), HDAC1, 2 and 3 (HDAC antibody sampler kit, cat. no. 9928; dilutions 1:1,000, 1:1,000 and 1:500, respectively; Cell Signaling Technology, Inc., Danvers, MA, USA) and HDAC10 (1:500; cat. no. BS1161; Bioworld Technology Inc., St. Louis Park, $\mathrm{MN}, \mathrm{USA})$ at $4^{\circ} \mathrm{C}$ overnight. Following incubation with a 
Table I. Drug dilutions in growth inhibition assay.

\begin{tabular}{lcccccc}
\hline Items & Chidamid $(\mu \mathrm{M})$ & $5-\mathrm{FU}(\mu \mathrm{M})$ & $\mathrm{CDDP}(\mu \mathrm{M})$ & $\operatorname{GEM}(\mu \mathrm{M})$ & VNR $(\mathrm{nM})$ & TAX $(\mathrm{nM})$ \\
\hline A549 & $0 / 2.5 / 5 / 10 / 20$ & $0 / 2.5 / 5 / 7.5 / 10$ & $0 / 2.5 / 5 / 10 / 20$ & $0 / 0.01 / 0.1 / 0.5 / 1$ & $0 / 1 / 10 / 100 / 500$ & $0 / 0.01 / 0.1 / 1 / 5$ \\
A549-CHI-R & $0 / 25 / 50 / 75 / 100$ & $0 / 2.5 / 5 / 7.5 / 10$ & $0 / 2.5 / 5 / 10 / 20$ & $0 / 0.01 / 0.1 / 1 / 10$ & $0 / 1 / 10 / 100 / 1000$ & $0 / 1 / 10 / 100 / 500$ \\
\hline
\end{tabular}

5-FU, 5-fluorouracil; CDDP, cis-platinum; GEM, gemcitabine; VNR, vinorelbine; TAX, paclitaxel; A549-CHI-R, chidamide-resistant A549 cells .

horseradish peroxidase (HRP)-conjugated secondary antibody (OriGene Technologies Inc., Rockville, MD, USA), including Anti-Mouse IgG/HRP (cat. no. TA130004; 1:3,000) or Anti-Rabbit IgG/HRP (cat. no. TA140003; 1:3,000) at room temperature for $2 \mathrm{~h}$, the membranes were developed using a luminol chemiluminescence detection kit (Santa Cruz Biotechnology Inc., Dallas, TX, USA) according to the manufacturer's protocol.

HDAC activity assay. HDAC activity was measured with the fluorometric HDAC Activity Assay kit (cat. no., ab156064; Abcam, Cambridge, UK) according to the manufacturer's protocol. Briefly, HDAC assay buffer containing a substrate peptide was incubated with HeLa nuclear extract (supplied with the kit) as a positive control, or A549 or A549-CHI-R nuclear extract, in a microtiter plate. Trichostatin A (supplied with the kit) was then added to the inhibitor control assay wells. At $20 \mathrm{~min}, 20 \mu \mathrm{l}$ developing solution was added to each well for a further $20 \mathrm{~min}$. Finally, $5 \mu \mathrm{l}$ stop buffer was added to every well and incubated for $30 \mathrm{~min}$ at room temperature. At the end of the treatment, plates were detected using fluorescence filters (excitation, $355 \mathrm{~nm}$; emission, $480 \mathrm{~nm}$ ).

Cell cycle arrest. Cells were then plated onto 6-well plates, allowed to attach for $24 \mathrm{~h}$ and then treated with $1 \mathrm{nM}$ TAX or $20 \mathrm{nM}$ VNR. At $72 \mathrm{~h}$, the cells were harvested and washed with saline then centrifuged at $335 \mathrm{x}$ g for $5 \mathrm{~min}$ at $4^{\circ} \mathrm{C}$. The pellets were re-suspended in $300 \mu \mathrm{l}$ of saline and were fixed by adding $700 \mu \mathrm{l}$ of cold absolute ethanol and incubating at $-20^{\circ} \mathrm{C}$ overnight. The next day, the cells were centrifuged at $335 \mathrm{x}$ g for $5 \mathrm{~min}$ at $4^{\circ} \mathrm{C}$ and the supernatant was removed. The cells were washed with cold saline twice, stained with propidium iodide on ice for $20 \mathrm{~min}$ and analyzed with a flow cytometer (BD LSR II system; BD Biosciences, Franklin Lakes, NJ, USA).

Statistical analysis. Assays were performed in triplicate, and results are presented as the mean \pm standard deviation. Statistical difference was assessed using Student's t-test (GraphPad_Prism V5.0; GraphPad Software Inc., La Jolla, CA, USA). $\mathrm{P}<0.05$ was considered to indicate a statistically significant difference.

\section{Results}

Establishment of a chidamide-resistant non-small cell lung cancer cell line. To investigate the acquired resistance to chidamide in cancer therapy, a chidamide-resistant lung cancer cell line, A549-CHI-R, was established (Fig. 1). When treated with $5 \mu \mathrm{M}$ chidamide, the morphology of A549-CHI-R cells became elongated and thin (Fig. 1A). The $\mathrm{IC}_{50}$ values of chidamide for A549-CHI-R and parental A549 cells were 78.34 and 9.07, respectively. A549-CHI-R was $\sim 9$-fold more resistant to chidamide compared with the parental A549 cells (Fig. 1B). Following 10 days of chidamide treatment, parental A549 cells exhibited markedly decreased colony formation rates $(\mathrm{P}<0.001)$ compared with untreated controls, whereas colony formation inhibition was not observed in the A549-CHI-R cell line (Fig. 1C). The colony formation rates for A549/CHI $5 \mu \mathrm{M}$, A549/DMSO, A549-CHI-R/CHI $5 \mu \mathrm{M}$ and A549-CHI-R/DMSO cells were 3.5, 56.9, 26.5 and 26.9\%, respectively (Fig. 1D).

HDAC1 protein degradation is inhibited in chidamideresistant lung cancer cells. Intracellular HDAC activity was examined in the parental and resistant cell lines. The HDAC activity in the A549-CHI-R cells was 1.77-fold higher than in the parental A549 cells (Fig. 2A). Western blot analysis revealed that HDAC protein expression was markedly increased in the A549-CHI-R cells compared with the parental A549 cells (Fig. 2B). To analyze the mechanisms of HDAC activity increase in A549-CHI-R cells, protein synthesis was first inhibited by CHX. HDAC1 protein expression became negligible after $24 \mathrm{~h}$ in parental A549 cells (Fig. 2C, left panel), but slightly decreased after $24 \mathrm{~h}$ in A549-CHI-R cells (Fig. 2C, right panel). However, HDAC2 protein was slightly increased in parental A549 and A549-CHI-R cells after $24 \mathrm{~h}$. These results indicated that the increased HDAC1 activity in A549-CHI-R cells was not induced by protein synthesis, but by the inhibition of protein degradation.

HDAC1 contributes to chidamide resistance in lung cancer cells. To investigate the pivotal role of HDAC1 in chidamide resistance, HDAC1 was overexpressed in A549 cells. The protein overexpression was confirmed by western blot analysis (Fig. 3A). Compared with parental cells, HDAC1-overexpressing cells exhibited $\sim 1.5$-fold increased intracellular HDAC activity $(\mathrm{P}<0.05$; Fig. $3 \mathrm{~B})$. Following $5 \mu \mathrm{M}$ of chidamide treatment, the survival rate of HDAC1-overexpressing A549 cells was 1.2-fold higher than the parental A549 cells ( $\mathrm{P}<0.01$; Fig. $3 \mathrm{C})$, indicating that the overexpression of HDAC1 contributed to chidamide resistance.

HDAC1 was then knocked out in the chidamide-resistant A549-CHI-R cell line. HDAC1 protein decreased in HDAC1-knockout A549-CHI-R cells (Fig. 3D). Compared with A549-CHI-R cells, intracellular HDAC activity rate was decreased to 0.27-fold following HDAC1-knockout (Fig. 3E). When treated with $50 \mu \mathrm{M}$ chidamide, the survival rate of 
A A549

549-CHI-R
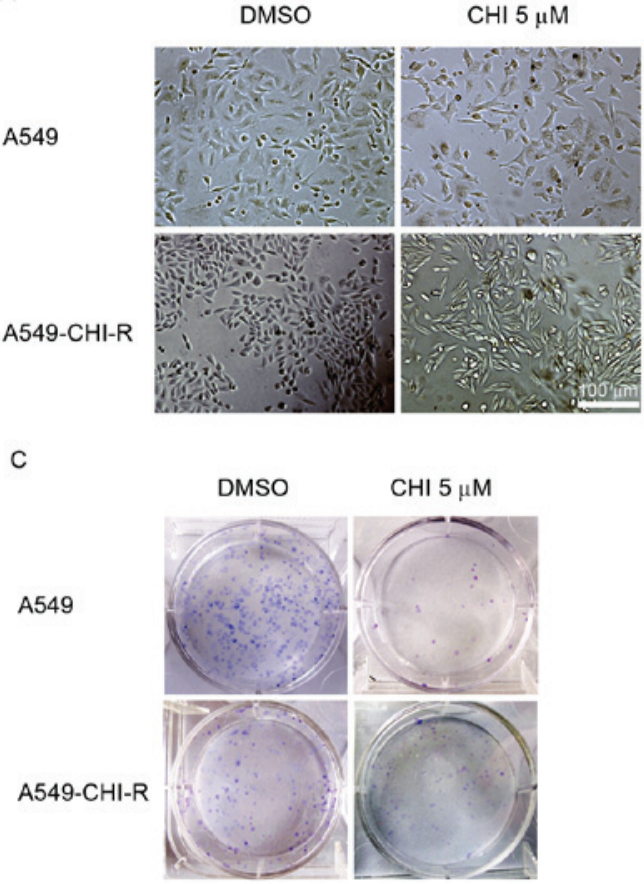

B
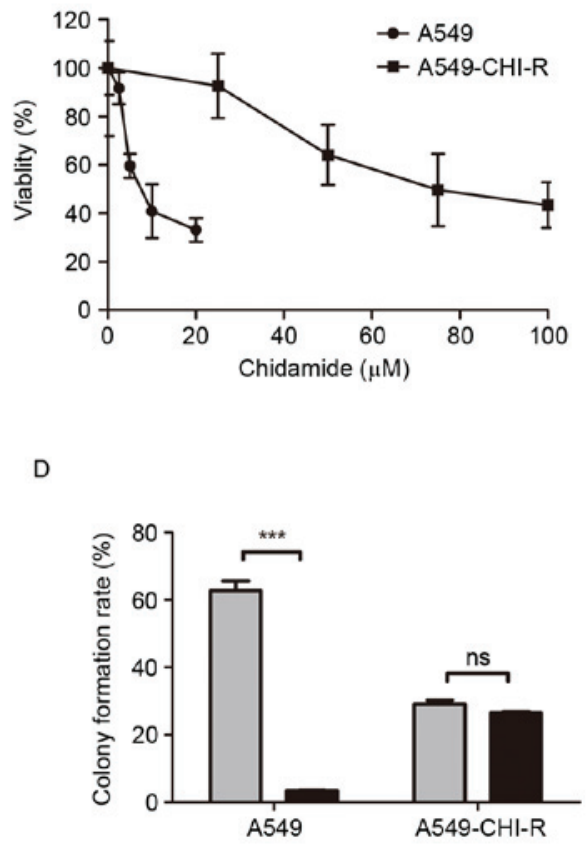

Figure 1. Establishment of a chidamide-resistant cell line. A549 cells were continuously exposed to gradually increasing chidamide concentrations of $4,8,16$, 32 and $64 \mu \mathrm{M}$ for $\sim 6$ months, and a chidamide-resistant lung cancer cell line (A549-CHI-R) was established. (A) Representative bright field images of parental A549 and A549-CHI-R cells. Cells were treated with or without $5 \mu \mathrm{M}$ chidamide for $40 \mathrm{~h}$. (B) Cell survival curves of A549 and A549-CHI-R cells. Cells were treated with a range of concentrations of chidamide for $72 \mathrm{~h}$. (C) Colony formation of parental A549 and A549-CHI-R cells. Parental A549 cells exhibited decreased colony formation following $5 \mu \mathrm{M}$ chidamide treatment for 10 days compared with A549-CHI-R cells. (D) Quantified colony formation assay for parental A549 and A549-CHI-R cells. ${ }^{* * *} \mathrm{P}<0.001$ between control and chidamide-treated cells. A549-CHI-R, chidamide-resistant A549 cells; DMSO, dimethyl sulfoxide; $\mathrm{CHI}$, chidamide; ns, no significance.

HDAC1-knockout A549-CHI-R cells was 0.32-fold lower than the A549-CHI-R cells ( $\mathrm{P}<0.01$; Fig. 3F).

Cross-resistance of the chidamide-resistant lung cancer cell line. It was investigated whether the chidamide-resistant A549-CHI-R cell line was cross-resistant to other chemotherapeutic drugs. $\mathrm{IC}_{50}$ values revealed that A549-CHI-R cells remained sensitive to CDDP and 5-FU. However, compared with the parental A549 cell line, the A549-CHI-R cells were 10.55-, 13.23- and $>100$-fold $(\mathrm{P}<0.01)$ more resistant to GEM, VNR and TAX, respectively (Table II).

The cell cycle of A549-CHI-R and A549 cells was analyzed by flow cytometry. Cells were incubated with $1 \mathrm{nM}$ TAX or $20 \mathrm{nM}$ VNR for $72 \mathrm{~h}$. Compared with untreated cells, the percentage of A549 cells in the G2/M phase markedly increased, from $28.2 \%$ to 77.7 (TAX) and $79.4 \%$ (VNR). However, following the same treatment, compared with control cells, the percentage of A549-CHI-R cells in the G2/M phase increased from 30.5 to 52.1 and $42.3 \%$. Therefore, A549-CHI-R cells were more resistant to G2/M arrest caused by TAX and VNR (Table III).

\section{Discussion}

In the present study, a chidamide-resistant NSCLC cell line, A549-CHI-R, was established. With growth inhibition and colony formation assays, it was revealed that A549 and A549-CHI-R cell lines exhibited a $~ 9$-fold difference in sensitivity to chidamide $\left(\mathrm{IC}_{50}\right.$ of A549 cell line, $9.07 \mu \mathrm{M} ; \mathrm{IC}_{50}$ of the A549-CHI-R cell line, $78.34 \mu \mathrm{M}$ ). Compared with parental A549 cells, A549-CHI-R cells exhibited a slower growth rate and a reduced colony formation rate. A previous study demonstrated that HL-60/LR cells, human acute myeloid leukemia cells resistant to LAQ824 (a hydroxamic acid analog pan-HDACi), exhibited a markedly higher growth compared with parental HL-60 cells (21). A vorinostat-induced subline, HCT116/vorinostat, exhibited a slightly slower growth rate compared with the parental HCT116 cell line (20). The different results indicate that the growth rate of HDACi-resistant cell lines may be drug-specific, cell type-specific or even case-specific.

A number of HDACi-resistant cancer cell lines have already been reported $(20,21,25)$. The mechanisms of HDACi resistance include the upregulation of P-glycoprotein, other ATP-binding cassette transporters, cell cycle proteins and signaling proteins, alterations to HDAC protein level, increases in thioredoxin level, nuclear factor- $\kappa \mathrm{B}$ activation and anti-apoptotic/prosurvival mechanisms (26). The molecular mechanism for acquired resistance varies in different HDACi-resistant cells. The acquired resistance of HCT116/VOR cells was associated with a reduction in histone acetylation, G2/M checkpoint activation and apoptosis susceptibility (20). Pan-HDACi-resistant HL-60/LR cells expressed higher levels of HDAC1, 2 and 4, but lacked expression of HDAC6, with concomitant hyper-acetylation of heat shock protein 90 (21).

Chidamide was revealed to be a low nanomolar inhibitor of HDAC1, 2, 3 and 10 (15). HDAC1 belongs to class I 
A
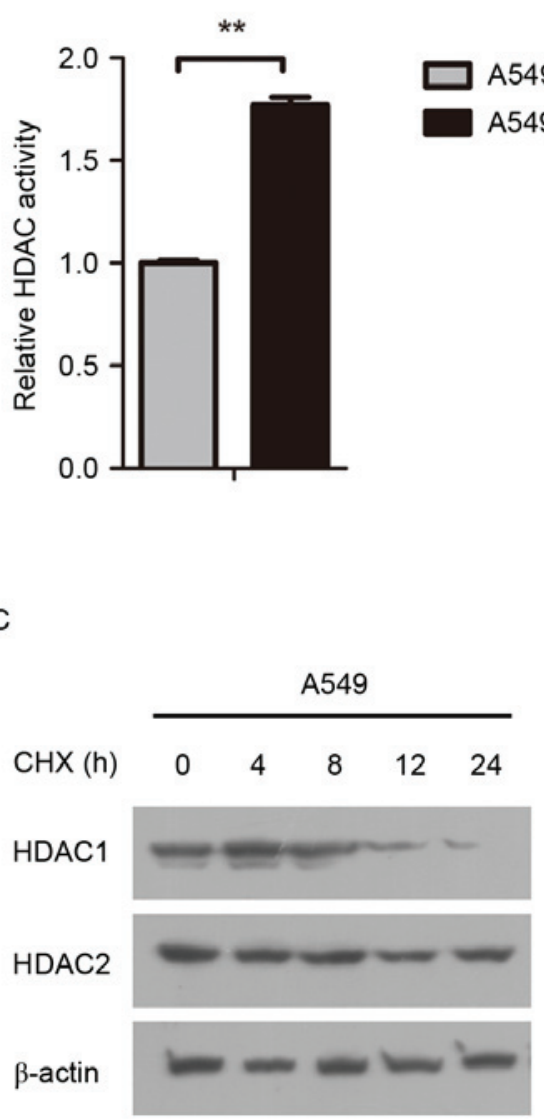

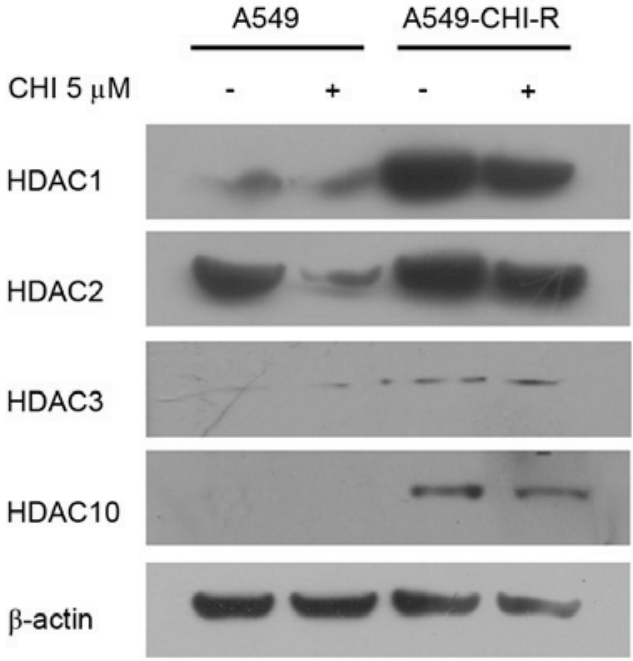

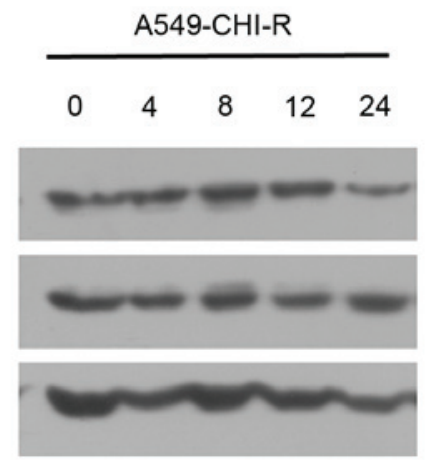

Figure 2. HDAC protein accumulation in CHI-resistant lung cancer cells. (A) HDAC activity of A549 and A549-CHI-R cells. (B) Western blot analysis of HDACs with or without $5 \mu \mathrm{M}$ CHI treatment for $72 \mathrm{~h}$. (C) Protein level of HDAC1 and 2 in A549 and A549-CHI-R cells incubated with $10 \mu \mathrm{g} / \mathrm{ml} \mathrm{CHX} \mathrm{for} \mathrm{the}$ indicated times. " $\mathrm{P}<0.005$ vs. A549 cells. HDAC, histone deacetylase; CHI, chidamide; A549-CHI-R, chidamide-resistant A549 cells; CHX, cycloheximide.

A

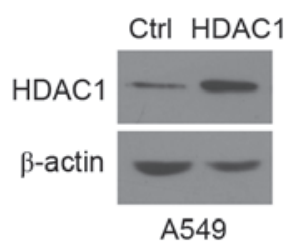

D

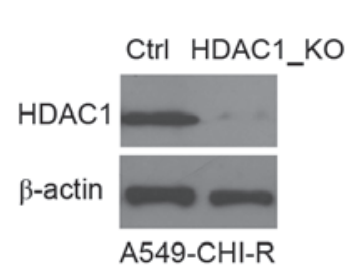

B

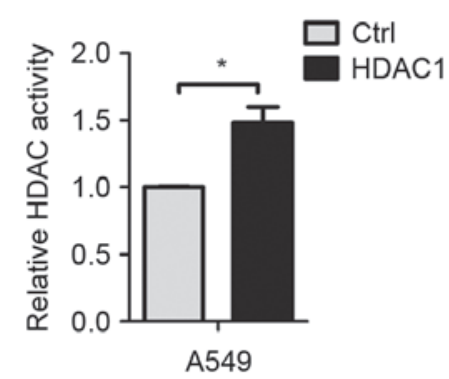

$\mathrm{E}$

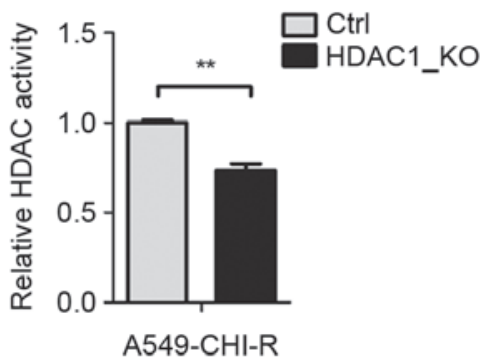

C

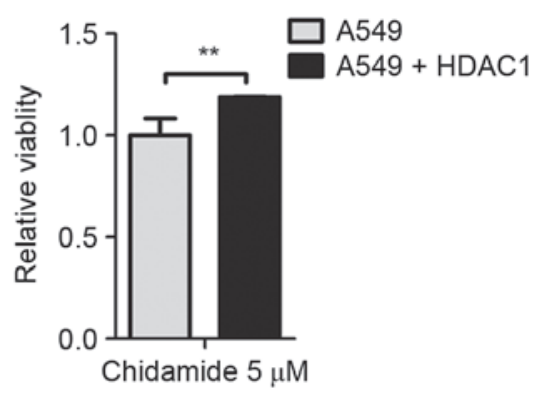

F

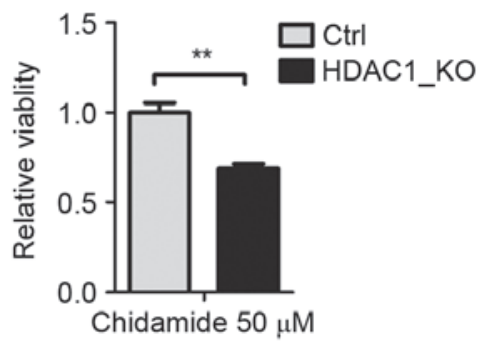

Figure 3. HDAC1 contributed to chidamide resistance in the A549 lung cancer cell line. (A) HDAC1 expression in A549 cells transfected with empty vector controls or a HDAC1 plasmid. (B) HDAC activity in A549 cells with or without HDAC1 overexpression. (C) Relative viability of HDAC1-overexpressing and parental A549 cells following treatment with $5 \mu \mathrm{M}$ chidamide for $72 \mathrm{~h}$. The (D) protein level of HDAC1, (E) relative HDAC activity and (F) relative viability following treatment with $50 \mu \mathrm{M}$ chidamide for $72 \mathrm{~h}$ in A549-CHI-R and HDAC1-KO A549-CHI-R cells. "P<0.01 vs. control; * $\mathrm{P}<0.005$ vs. control or A549 cells. All experiments were performed three times. HDAC, histone deacetylase; KO, knockout; Ctrl, control; A549-CHI-R, chidamide-resistant A549 cells. 
Table II. Drug sensitivity in parental A549 and A549-CHI-R cells.

\begin{tabular}{|c|c|c|c|c|c|}
\hline \multirow[b]{2}{*}{ Drug } & \multicolumn{2}{|c|}{ A549 } & \multicolumn{2}{|c|}{ A549-CHI-R } & \multirow[b]{2}{*}{ Resistance index } \\
\hline & $\mathrm{IC}_{50}$ & $95 \% \mathrm{CI}$ & $\mathrm{IC}_{50}$ & $95 \% \mathrm{CI}$ & \\
\hline Chidamide & 9.07 & $6.00-11.32$ & 78.34 & $51.30-111.87$ & 8.64 \\
\hline 5-fluorouracil & 4.03 & $2.09-7.75$ & 5.17 & $2.77-7.58$ & 1.28 \\
\hline Cisplatin & 9.13 & $8.90-9.37$ & 7.87 & $5.75-10.76$ & 0.86 \\
\hline Gemcitabine & 0.21 & $0.01-3.65$ & 2.25 & $1.67-3.03$ & 10.55 \\
\hline Vinorelbine & 31.06 & $11.32-85.17$ & 411.00 & $282.10-598.80$ & 13.23 \\
\hline Paclitaxel & 0.89 & $0.11-1.98$ & 123.40 & $6.00-260.00$ & 123.40 \\
\hline
\end{tabular}

Sensitivity to the drugs was determined by MTT assay after $72 \mathrm{~h}$. Resistance index is a comparison between the $\mathrm{IC}_{50}$ for the drug in A549-CHI-R cells and the $\mathrm{IC}_{50}$ for the parental A549 cells. A549-CHI-R, chidamide-resistant A549 cells; CI, confidence interval.

Table III. Effects of TAX or VNR on the cell cycle distribution in parental A549 and A549-CHI-R cells.

\begin{tabular}{lrrrrrrr}
\hline & \multicolumn{3}{c}{ A549 cells, } & & \multicolumn{3}{c}{ A549-CHI-R cells, } \\
\cline { 2 - 3 } Cell cycle phase & Ctrl & TAX & VNR & & Ctrl & TAX & VNR \\
\hline Sub-G1 & 1.7 & 0.3 & 0.5 & 0.2 & 0.1 & 0.1 \\
G1 & 60.2 & 15.1 & 10.8 & 53.4 & 34.8 & 41.7 \\
S & 9.9 & 6.9 & 9.3 & 15.9 & 13.0 & 15.9 \\
G2/M & 28.2 & 77.7 & 79.4 & & 30.5 & 52.1 & 42.3 \\
\hline
\end{tabular}

Cell cycle distribution was examined by propidium iodide staining and analyzed with fluorescence-activated cell sorting. Data represent the results of three independent experiments. TAX, paclitaxel; VNR, vinorelbine; Ctrl, control; A549-CHI-R, chidamide-resistant A549 cells.

HDACs, which are the most closely associated with malignant phenotypes (27). HDAC1 overexpression has been reported to be positively associated with cell division, differentiation and tumorigenesis (28-30). Loss of HDAC1 resulted in a $60 \%$ reduction in total HDAC activity and a loss of stem cell viability (28). Consistently, total HDAC activity was also elevated in A549-CHI-R and A549 HDAC1-overexpressed cells. Similarly, HDAC1 was also accumulated in chidamide-resistant A549-CHI-R cells, consistent with other HDACi-resistant cells (23).

Post-translational modifications of HDAC have been demonstrated to perform pivotal roles in the regulation of gene expression. HDACs modified by ubiquitination are targeted for degradation (31). Certain chemicals can target HDAC1 to induce proteasome-mediated degradation (32). Specifically, treatment with diesel exhaust particulate induced degradation of HDAC1 in a human bronchial epithelial cell line, BEAS-2B (33). The present study reported a decreased degradation of HDAC1 in A549-CHI-R cells. Overexpression of HDAC1 in cervical cancer cells restrained cell proliferation and induced premature senescence (34). Taken together,
HDAC1 accumulation may be a predictive marker for the resistance to chidamide.

Cross-resistance is a common response to chemotherapy. HDACi-resistant cell lines, HL-60/LR and HCT116/vorinostat, exhibited cross-resistance to other HDACis $(20,21)$. Pemetrexed-resistant NSCLC cell lines exhibited cross-resistance to CDDP (35). A549-CHI-R cells, which exhibit enhanced HDAC activity, demonstrated cross-resistance to GEM, TAX and VNR in the present study. Consistent with this, paclitaxel-resistant NSCLC cells exhibited enhanced HDAC activity and tumorigenicity (36). Increased HDAC1 expression in NSCLC tissue predicted a poor prognosis for patients treated with paclitaxel (36). TAX and VNR are microtubule-targeting drugs; their most potent cytotoxic action is the suppression of microtubule dynamics, leading to mitotic arrest and subsequent cell death (37). Gong et al (38) demonstrated that chidamide inhibits cell proliferation by inducing cell cycle arrest. The present study revealed that G2/M arrest decreased in A549-CHI-R cells compared with parental A549 cells following treatment with TAX or VNR. However, the chidamide-resistant cells retained sensitivity and susceptibility to the drugs CDDP and 5-FU. These drugs induce cell death by inhibiting DNA synthesis $(39,40)$. A combination of CDDP or 5-FU with chidamide may synergistically induce apoptosis $(17,18)$. The results of the present study are consistent with these previous studies.

In conclusion, a chidamide-resistant cell line was established, and it was proposed that HDAC1 accumulation may contribute to chidamide resistance. In addition, the chidamide-resistant cell line remained sensitive to 5-FU and CDDP, but cross-resistant to TAX and VNR, indicating a potential strategy for cancer therapy.

\section{Acknowledgements}

The present study was supported by the National Natural Science Foundation (grant nos. 81321091, 81452761 and 31171322) and the National Basic Research Program of China (grant no. 2011CB910700704). The authors thank Shenzhen ChipScreen Biosciences Ltd., (Shenzhen, China) for providing chidamide used in the present study. 


\section{References}

1. Bolden JE, Peart MJ and Johnstone RW: Anticancer activities of histone deacetylase inhibitors. Nat Rev Drug Discov 5: 769-784, 2006.

2. Glozak MA and Seto E: Histone deacetylases and cancer. Oncogene 26: 5420-5432, 2007.

3. Song J, Noh JH, Lee JH, Eun JW, Ahn YM, Kim SY, Lee SH, Park WS, Yoo NJ, Lee JY and Nam SW: Increased expression of histone deacetylase 2 is found in human gastric cancer. APMIS 113: 264-268, 2005.

4. Toh Y, Yamamoto M, Endo K, Ikeda Y, Baba H, Kohnoe S, Yonemasu H, Hachitanda Y,Okamura T and Sugimachi K: Histone $\mathrm{H} 4$ acetylation and histone deacetylase 1 expression in esophageal squamous cell carcinoma. Oncol Rep 10: 333-338, 2003.

5. Giannini R and Cavallini A: Expression analysis of a subset of coregulators and three nuclear receptors in human colorectal carcinoma. Anticancer Res 25: 4287-4292, 2005.

6. Waltregny D, North B, Van Mellaert F, de Leval J, Verdin E and Castronovo V: Screening of histone deacetylases (HDAC) expression in human prostate cancer reveals distinct class I HDAC profiles between epithelial and stromal cells. Eur J Histochem 48: 273-290, 2004

7. Bartling B, Hofmann HS, Boettger T, Hansen G, Burdach S, Silber RE and Simm A: Comparative application of antibody and gene array for expression profiling in human squamous cell lung carcinoma. Lung Cancer 49: 145-154, 2005.

8. Sharma S, Kelly TK and Jones PA: Epigenetics in cancer. Carcinogenesis 31: 27-36, 2010.

9. Garber K: Purchase of Aton spotlights HDAC inhibitors. Nat Biotechnol 22: 364-365, 2004.

10. Duvic M and Vu J: Vorinostat: A new oral histone deacetylase inhibitor approved for cutaneous T-cell lymphoma. Expert Opin Investig Drugs 16: 1111-1120, 2007.

11. Grant C, Rahman F, Piekarz R, Peer C, Frye R, Robey RW, Gardner ER, Figg WD and Bates SE: Romidepsin: A new therapy for cutaneous T-cell lymphoma and a potential therapy for solid tumors. Expert Rev Anticancer Ther 10: 997-1008, 2010.

12. Poole RM: Belinostat: First global approval. Drugs 74: 1543-1554, 2014.

13. Lee JH, Choy ML and Marks PA: Mechanisms of resistance to histone deacetylase inhibitors. Adv Cancer Res 116: 39-86, 2012.

14. Shi Y, Dong M, Hong X, Zhang W, Feng J, Zhu J, Yu L, Ke X, Huang H, Shen Z, et al: Results from a multicenter, open-label, pivotal phase II study of chidamide in relapsed or refractory peripheral T-cell lymphoma. Ann Oncol 26: 1766-1771, 2015.

15. Ning ZQ, Li ZB, Newman MJ, Shan S, Wang XH, Pan DS, Zhang J, Dong M, Du X and Lu XP: Chidamide (CS055/HBI-8000): A new histone deacetylase inhibitor of the benzamide class with antitumor activity and the ability to enhance immune cell-mediated tumor cell cytotoxicity. Cancer Chemother Pharmacol 69: 901-909, 2012

16. Dong M, Ning ZQ, Xing PY, Xu JL, Cao HX, Dou GF, Meng ZY, Shi YK, Lu XP and Feng FY: Phase I study of chidamide (CS055/HBI-8000), a new histone deacetylase inhibitor, in patients with advanced solid tumors and lymphomas. Cancer Chemother Pharmacol 69: 1413-1422, 2012.

17. Zhou Y, Pan DS, Shan S, Zhu JZ, Zhang K, Yue XP, Nie LP, Wan J, Lu XP, Zhang W and Ning ZQ: Non-toxic dose chidamide synergistically enhances platinum-induced DNA damage responses and apoptosis in non-small-cell lung cancer cells. Biomed Pharmacother 68: 483-491, 2014.

18. Liu L, Qiu S, Liu Y, Liu Z, Zheng Y, Su X, Chen B and Chen H: Chidamide and 5-flurouracil show a synergistic antitumor effect on human colon cancer xenografts in nude mice. Neoplasma 63: 193-200, 2016.

19. Wang H, Guo Y, Fu M, Liang $X$, Zhang $X$, Wang $R$, Lin $C$ and Qian H: Antitumor activity of Chidamide in hepatocellular carcinoma cell lines. Mol Med Rep 5: 1503-1508, 2012.

20. Dedes KJ, Dedes I, Imesch P, von Bueren AO, Fink D and Fedier A: Acquired vorinostat resistance shows partial cross-resistance to 'second-generation' HDAC inhibitors and correlates with loss of histone acetylation and apoptosis but not with altered HDAC and HAT activities. Anticancer Drugs 20: 321-333, 2009.

21. Fiskus W, Rao R, Fernandez P, Herger B, Yang Y, Chen J, Kolhe R, Mandawat A, Wang Y, Joshi R, et al: Molecular and biologic characterization and drug sensitivity of pan-histone deacetylase inhibitor-resistant acute myeloid leukemia cells. Blood 112: 2896-2905, 2008.
22. Xiao JJ, Huang Y, Dai Z, Sadée W, Chen J, Liu S, Marcucci G, Byrd J, Covey JM, Wright J, et al: Chemoresistance to depsipeptideFK228[(E)-(1S,4S,10S,21R)-7-[(Z)-ethylidene]-4,21diisopropyl-2-oxa-12,13-dithia-5,8,20,23-tetraazabicyclo[8,7,6]tricos-16-ene-3,6,9,22-pentanone] is mediated by reversible MDR1 induction in human cancer cell lines. J Pharmacol Exp Ther 314: 467-475, 2005.

23. Yamada H, Arakawa Y, Saito S, Agawa M, Kano Y and Horiguchi-Yamada J: Depsipeptide-resistant KU812 cells show reversible P-glycoprotein expression, hyper-acetylated histones, and modulated gene expression profile. Leukemia Res 30: 723-734, 2006

24. Juengel E, Makarević J, Tsaur I, Bartsch G, Nelson K, Haferkamp A and Blaheta RA: Resistance after chronic application of the HDAC-inhibitor valproic acid is associated with elevated Akt activation in renal cell carcinoma in vivo. PLoS One 8: e53100, 2013.

25. Zhu Y, Das K, Wu J, Lee $\mathrm{MH}$ and Tan P: RNH1 regulation of reactive oxygen species contributes to histone deacetylase inhibitor resistance in gastric cancer cells. Oncogene 33: 1527-1537, 2014.

26. Robey RW, Chakraborty AR, Basseville A, Luchenko V, Bahr J, Zhan Z and Bates SE: Histone deacetylase inhibitors: Emerging mechanisms of resistance. Mol Pharm 8: 2021-2031, 2011.

27. Nakagawa M, Oda Y, Eguchi T, Aishima S, Yao T, Hosoi F, Basaki Y, Ono M, Kuwano M, Tanaka M and Tsuneyoshi M: Expression profile of class I histone deacetylases in human cancer tissues. Oncol Rep 18: 769-774, 2007.

28. Jamaladdin S, Kelly RD, O'Regan L, Dovey OM, Hodson GE, Millard CJ, Portolano N, Fry AM, Schwabe JW and Cowley SM: Histone deacetylase (HDAC) 1 and 2 are essential for accurate cell division and the pluripotency of embryonic stem cells. Proc Natl Acad Sci USA 111: 9840-9845, 2014.

29. Choi JH, Kwon HJ, Yoon BI, Kim JH, Han SU, Joo HJ and Kim DY: Expression profile of histone deacetylase 1 in gastric cancer tissues. Jpn J Cancer Res 92: 1300-1304, 2001.

30. Korfei M, Skwarna S, Henneke I, MacKenzie B, Klymenko O, Saito S, Ruppert C, von der Beck D, Mahavadi P, Klepetko W, et al: Aberrant expression and activity of histone deacetylases in sporadic idiopathic pulmonary fibrosis. Thorax 70: 1022-1032, 2015.

31. Seigneurin-Berny D, Verdel A, Curtet S, Lemercier C, Garin J, Rousseaux $\mathrm{S}$ and Khochbin $\mathrm{S}$ : Identification of components of the murine histone deacetylase 6 complex: Link between acetylation and ubiquitination signaling pathways. Mol Cell Biol 21: 8035-8044, 2001

32. Liu D, Zhou P, Zhang L, Zheng Y and He F: HPV16 activates the promoter of Oct4 gene by sequestering HDAC1 from repressor complex to target it to proteasomal degradation. Med Hypotheses 79: 531-534, 2012.

33. Cao D, Bromberg PA and Samet JM: COX-2 expression induced by diesel particles involves chromatin modification and degradation of HDAC1. Am J Respir Cell Mol Biol 37: 232-239, 2007.

34. Chuang JY and Hung JJ: Overexpression of HDAC1 induces cellular senescence by $\mathrm{Sp} 1 / \mathrm{PP} 2 \mathrm{~A} / \mathrm{pR}$ b pathway. Biochem Biophys Res Commun 407: 587-592, 2011.

35. Zhang D, Ochi N, Takigawa N, Tanimoto Y, Chen Y, Ichihara E, Hotta K, Tabata M, Tanimoto M and Kiura K: Establishment of pemetrexed-resistant non-small cell lung cancer cell lines. Cancer Lett 309: 228-235, 2011.

36. Wang L, Li H, Ren Y, Zou S, Fang W, Jiang X, Jia L, Li M, Liu X, Yuan X, et al: Targeting HDAC with a novel inhibitor effectively reverses paclitaxel resistance in non-small cell lung cancer via multiple mechanisms. Cell Death Dis 7: e2063, 2016.

37. Jordan MA and Wilson L: Microtubules as a target for anticancer drugs. Nat Rev Cancer 4: 253-265, 2004.

38. Gong K, Xie J, Yi H and Li W: CS055 (Chidamide/HBI-8000), a novel histone deacetylase inhibitor, induces G1 arrest, ROS-dependent apoptosis and differentiation in human leukaemia cells. Biochem J 443: 735-746, 2012.

39. Sorenson CM and Eastman A: Mechanism of cis-diamminedi chloroplatinum(II)-induced cytotoxicity: Role of G2 arrest and DNA double-strand breaks. Cancer Res 48: 4484-4488, 1988.

40. Santi DV, McHenry CS and Sommer H: Mechanism of interaction of thymidylate synthetase with 5-fluorodeoxyuridylate. Biochemistry 13: 471-481, 1974. 